\title{
Research and Exploration on the Reform of Medical Marketing Course Teaching Mode based on MOOCs Perspective
}

\author{
Qian yang ${ }^{1}$, Guang chen, Lan luo* \\ 1School of Economics and Management, Jiangxi University of Traditional Chinese Medicine, \\ Nanchang, 330004, China \\ *Corresponding author, e-mail: cguang@ foxmail.com
}

\begin{abstract}
MOOCs is a kind of new teaching mode of traditional classroom teaching mode innovation. By analyzing the current situation of the development of MOOCs in China, this paper expounds its influence and challenge to the existing teaching mode, and put forward corresponding related development countermeasures of pharmaceutical marketing teaching, hoping to provide reference for the construction of the teaching mode of pharmaceutical marketing.
\end{abstract}

Keywords—Pharmaceutical marketing; MOOCs; flipping class

\section{INTRODUCTION}

The teaching process is essentially a process of communication, by whatever means, teachers can choose the appropriate teaching methods, curriculum concept, skills transfer to the students; the students according to their own understanding of teachers to selectively receive the message, eventually formed their own knowledge system. With the popularity of the rapid development of information technology and the mobile terminal tool, MOOC online learning has become a new way of learning, has gradually attracted people's attention, as a way of students' mobile learning, it breaks the fixed time and place obstacle.

\section{THE INFLUENCE AND ENLIGHTENMENT OF MOOCS ON THE CURRENT EDUCATIONAL MODEL}

\section{A. The meaning of MOOCs}

MOOC (Massive Online Open Courses) is a large-scale network open course each English word acronym, is a kind of new teaching mode of traditional classroom teaching mode innovation. Since 2012, some top universities in the United States combine Coursera, Udacity and edX three courses providers to provide online learning courses for students or scholars, so that users can learn knowledge systematically, flexibly and flexibly. MOOC, as a new form of education, is changing the traditional teaching model of the entity class, which is very suitable for the current network learning trend.

\footnotetext{
* This paper is the research result of the school education reform project
} (2013jzjg-12).

\section{B. The difference between MOOCs and the current teaching model}

(1) MOOCs embodies student centered Idea and value orientation and pays attention to the individualization of teaching. This coincides with the value orientation of "peopleoriented" in modern undergraduate teaching. MOOC courses according to the learners' own time free arrangements, learners can access the MOOC on all courses whenever and wherever possible, breaking the fixed time schools and obstacles to learning. To learn new knowledge, can also carry on the knowledge gaps [1].

(2) MOOC embodies the idea of sharing high quality teaching resources, which is in accordance with the value orientation of modern undergraduate teaching. The courses on MOOC platform are all online high-quality curriculum resources. Through the online courses offered by MOOC, more learners can learn more courses that some top university teachers teach. MOOC has the characteristics of open and sharing, and the idea that everyone can learn is recognized by people all over the world.

(3) MOOC pays more attention to the scientificity of evaluation. The premise of improving teaching is scientific evaluation. In teaching evaluation, MOOC adopts diversified evaluation methods and diversified evaluation subjects, emphasizing self-assessment and peer review. Evaluation process can also indirectly reflect students' own learning effect.

\section{The problems existing in the application of $M O O C$ in the current teaching reform}

Although MOOC has many advantages, it fits the value orientation of modern teaching in some ideas and is of great value to the reform of teaching, but there are also some problems. First of all, it is difficult to realize the value orientation of the tree moral educating people through the teaching of MOOC completely. Teachers and students can't face to face communication, but they are not effective in educating people and emotional cultivation. Moreover, teachers can't catch students' learning situation in real time, so it is hard to make appropriate adjustments accordingly. The essence of MOOC is online teaching and learning based on the Internet, and learners need to learn through computer or 
other network terminal devices. Therefore, it is necessary to watch and learn under the circumstances of the network. For areas without network coverage, this way of learning can not be realized.

\section{THE INFLUENCE AND CHALLENGE OF MOOCS MODEL ON THE TEACHING OF MEDICAL MARKETING COURSE}

In the background of MOOC, the application of micro class in the course of medical marketing is in line with the development of network, opening and education information. MOOC teaching platform pharmaceutical marketing professional to relying on a large number of open network information resources, guide students autonomous mobile learning, can effectively encourage students to find, analyze and solve problems, the unlimited learning and communication to solve the marketing problems faced by the traditional education.

\section{A. Problems existing in the course of medical marketing course}

Compared with other courses, the most prominent of the related courses in medical marketing is its practicality or practicality. The basic theoretical knowledge and methods of medical marketing major are the summary of the staff's experience in marketing practice. Through the study of the medical marketing course, students need to adapt to the demand of the modern market and become qualified modern enterprise employees with marketing ability. However, in the traditional classroom teaching, results in poor results due to the outdated teaching materials, improper teaching methods and teachers' lack of practical experience.[3]Based on the background of information fragmentation in the era of Internet, the course of pharmaceutical marketing can not stay in the transmission of one-way knowledge to students. It needs active exploration and integration, integrating information technology and pharmaceutical marketing specialty.

\section{1) Textbooks are out of date}

Most of students' use of marketing materials, such as the theory of marketing materials $<>1990$ s some successful American marketing experts, and marketing culture and local environment are inseparable, the classic case in the U.S., may not be suitable for Chinese.

\section{2) Improper teaching methods}

The course teaching is short of communication with the students, and the students' learning is compelled. Some courses pay much attention to the theoretical research of pharmaceutical marketing, while ignoring the practical ability of students, such as research, market segmentation, market positioning, product promotion and so on. [4] causes students to lack practical ability in their work.

\section{B. The impact and influence of the MOOCs model on the current course teaching}

This new way of teaching on students' learning mode will have a great change, teachers to provide teaching video as the main form of learning resources for students to watch online video, with teachers and students in the network, students interaction between students and teachers to complete online testing work preset, online examinations. This is considered to be subversion of "class teaching + after-school students homework" teaching mode.

\section{1) Put forward more challenges to many of the current} teache

The teaching of medical marketing related courses is very practical. But some of the pharmaceutical marketing teachers in some universities lack experience in the management of enterprises, without relevant social practice experience, resulting in some teachers' teaching can not be combined with practice. And traditional teaching mode that $\mathrm{Mu}$ class information has essential difference. The traditional teaching mode and teaching mode of the $\mathrm{Mu}$ class information is essentially different, Mark Plinski had the characteristics of positioning after 1980 born into "instant, interactive, virtual sex", they were born in the digital age, naturally adapt to the digital, but before most of the Mu class teacher was born in 1980. They grow up in the non digital era, acquired through efforts to learn to adapt to the new technology.[5] It can be said, for them, that they have a sense of indescribable distance to the digital age. Due to the continuous development of economy and the continuous progress of science and technology, the emergence of many new media, new technologies and new theories makes the frontiers of disciplines change constantly. Then, as a professional teacher, it is sometimes difficult for them to fully grasp this. Especially considering the relatively few sources of information in some local colleges and universities, the teachers' personal strength is difficult to realize the timely and rapid renewal of the theory. The application of admiring lessons will also change the teaching system and reduce the demand for teaching of some teachers by [6].

\section{2) The shortage of existing shared resources}

Teaching philosophy needs to turn to value communication and cultural identity, and constantly expand students' sense of value and identity, and create a good communication environment for students. The education information development plan also points out that improving information technology plays an important role in education. Therefore, promoting the quality of higher education and putting forward higher requirements for resource sharing of pharmaceutical marketing major courses. However, at present, there are many practical difficulties in the development of MOOC class in China. Resource sharing and win-win situation are far from being formed. In addition, there is little sharing of courses between universities, which makes the scope of high-quality resources narrow, and it is difficult to achieve real resource sharing. 


\section{THINKING ON THE CONSTRUCTION OF MEDICAL MARKETING SPECIALTY COURSE UNDER THE BACKGROUND OF MOOCS}

Medical marketing related courses require students to consolidate their theoretical knowledge in practice. Under the background of MOOC, the micro lesson mode can make students consolidate their theoretical knowledge while emphasizing practice.

\section{A. The construction of marketing courses is centered on Students}

First of all, in curriculum development, we should pay attention to the online learning situation of online students, develop online courses that meet the characteristics of Mogao classes, and properly give students refined learning experience. In addition, in reference, pay more attention to the teaching idea and teaching forms of $\mathrm{Mu}$ class, changes in content organization, around the occupation education concept, the marketing task decomposition, according to the pharmaceutical marketing environment, planning, product positioning, communication and other issues to the case teaching driver, building a complete course of a new knowledge system.

\section{B. The construction of medical marketing courses, taking the turning of the classroom as a breakthrough point}

The characteristics of the flipping teaching in the course are more distinct, and under the condition of the Internet, the flipping course has the feasibility to implement. Marketing majors can make use of high quality Internet resources to improve their knowledge acceptance and abandon the form of relying solely on teaching teachers to acquire knowledge. The turnover of the classroom makes the teacher's role change, and the more responsibility of the teacher is to guide the students to use their knowledge. Focus on creating teaching video, dividing the major contents into several small part, made into a small video, it is convenient for students to use their spare time to learn. Actively organize the project activities to transfer the learning content to the students through the network classroom, so that the students can apply the content well in the high quality learning activities. The MOOC model is different from the traditional classroom teaching methods. It can mobilize the students' enthusiasm by asking questions, discussing and watching video. MOOC provides a variety of interactive communities for learners and the establishment of interactive participation mechanism to promote the transformation of students from past passive learners to active learners. Students can not only learn theoretical knowledge from their colleagues in practice, but also connect with course teachers through e-mail and other ways through MOOC platform, so as to enhance learning interaction [8].

\section{Building a mixed teaching model under the line of line}

Compared with the $\mathrm{Mu}$ class, network open class, are more interactive. The Mu class teaching, classroom teaching is no longer based on teaching. Teachers can make the content of medical marketing theory into video, so that students can be completed outside the classroom. In addition, students' interaction, discussion, and sharing are emphasized in the classroom."Market survey and forecast" course practice content is more, so the traditional classroom teaching has been unable to meet the needs of students. Actively introduce $\mathrm{Mu}$ class teaching, students can finish their theoretical study through watching videos, completing homework online and conducting online guidance in extracurricular activities, and conducting social surveys in a timely manner to complete teaching contents. In general, the Mu class line under mixed mode teaching can effectively promote the reflection of traditional teaching, but also to strengthen the research and exploration of the teaching mode to a certain extent. The pharmaceutical marketing related courses need to use the advantages of MOOC, through the video, discussion way to let the students to learn theoretical knowledge, and the online classroom, teachers and students should pay attention to solve the students do not understand the problem. MOOC can also monitor students' learning progress while explaining knowledge for students. Teachers can better arrange teaching tasks through different progress of each student. You can explore the course based on turnover Hybrid Teaching Model hall to carry out MOOC teaching localization pilot. "Mixed teaching model" refers to the teacher asked the students to online learning through the computer network, the line to return to the school classroom and corresponding course teachers, students interactive learning online and mixed teaching model. Teachers to provide teaching video and PPT teaching as the main form of learning resources, students of teaching video learning resources and learning in the classroom to watch, and related work practice tests; teachers and students to complete the homework in the classroom with paper, answering, collaboration and exploration study and conduct interactive communication, such as [9].

\section{CONCLUSION}

The quality of higher education is directly related to the professional occupation quality and ability, thus affecting the development and direction of the industry. Therefore, whether all links of higher education should focus on training objectives and whether it can provide students with the best way to acquire professional knowledge is the key to solve whether higher education can meet the needs of society and industry and cultivate qualified talents.MOOC was gradually known by people, and caused widespread concern in the education sector. Although a great wave of MOOC mode in the educational field of our country, but whether it is suitable for full-time students and teaching, and to completely replace the existing teaching mode, are the problems to be further studied [10]. Based on the characteristics of each course tailored, can not simply copy the.MOOCs .Although MOOCs has its advantages and limitations, it can't completely replace university education. More importantly, it brings us thinking about advancing teaching methods and methods and keeping pace with the times. 


\section{REFERENCES}

[1] Wang Yanping, "on Problems and solutions facing the education China ad, < China in 20102 human $>[\mathrm{J}]$. (In Chinese)

[2] Wei Xing, < research on innovative training model for applied advertising talents of Independent College $>,<>[\mathrm{J}]$ from Southeast Asia, 2 (period ninth of 110). (In Chinese)

[3] Han Pengfei, "the status and reform of advertising education in Colleges and universities in Jiangxi, >[D], May 2009." (In Chinese)

[4] Yang Qian, "an overview of the current status of T7 in American university advertising teaching, Journal $[\mathrm{J}]$ of Southeast University, Twelfth 2005." (In Chinese)

[5] Zheng Danping, Tsai son, "dance with the world -- the idealized model of the advertising course system," < Yunnan Institute of Finance and Commerce Journal $>[\mathrm{J}]$, third 2002. (In Chinese)
[6] Yuan Rong, <MOOC background micro lesson model in the marketing major teaching application analysis $><$ human resources development $>[\mathrm{J}]$, third phase of 2016. (In Chinese)

[7] Wang Zuyuan, he Bo, <MOOC localization feasibility and concern -Based on the MOOC platform of college physics curriculum hybrid teaching practice, Wanfang Data Platform, September 2014. (In Chinese)

[8] Condi, Wen Cui, Dai Minhong, < professional course of marketing in Higher Vocational Colleges - MOOC - teaching model research and exploration > education time and space. (In Chinese)

[9] Fei Wei, Wu Hongbin, Chen Weihong, He Jianxin, "MOOC based teaching research and practice of computer courses in Local Applied Colleges and universities", education and teaching forum, May 2015. (In Chinese)

[10] Incandescent, "teaching research and practice of computer courses in Local Applied Universities Based on MOOC", science and technology wind, April 2017. (In Chinese) 